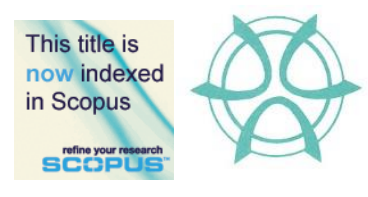

PLANNING MALAYSIA:

Journal of the Malaysian Institute of Planners

VOLUME 15 ISSUE 1 (2017), Page 139 - 150

\title{
ARCHITECTURAL HERITAGE RESTORATION OF RUMAH DATUK SETIA VIA MOBILE AUGMENTED REALITY RESTORATION
}

\author{
Aida Kesuma Azmin 1 , Mohd Hisyamuddin Kassim² ${ }^{2}$ Fadzidah Abdullah $^{3}, \&$ \\ Alliyah Nur Zafirah Sanusi1 ${ }^{4}$ \\ ${ }_{1,2,3,4}$ Kulliyyah of Architecture and Environmental Design, \\ INTERNATIONAL ISLAMIC UNIVERSITY MALAYSIA
}

\begin{abstract}
This paper focuses on Mobile Augmented Reality (MAR) for architectural heritage restoration as an alternative technique to visually restore the ruined rear house of Rumah Datuk Setia, Kuala Kangsar, Perak. The research consists of the development of Virtual Heritage $(\mathrm{VH})$ based on the architectural heritage information of the ruined rear house, such as spatial organization, construction, ornamentation, materials; as well as "Augmented Reality" (AR) for architectural heritage restoration via mobile devices, such as smartphone and tablet. The objective is to develop Mobile Augmented Reality Restoration (MARR) of Rumah Datuk Setia, as a showcase of architectural conservation technique, for future restoration. The study reveals the process by integrating layers of architectural heritage information - VH, MAR and other enabling technologies as primary mediums for architectural heritage restoration. The research manifestation introduces a new technique of architectural heritage building restoration through MARR. It highlights necessary elements needed to be considered, and challenges, in developing the MARR, which can be applied for future architectural restorations.
\end{abstract}

Keyword: Virtual heritage, mobile augmented reality, architectural heritage restoration

Date Received: $30^{\text {th }}$ April 2016

Date of Acceptance: $30^{\text {th }}$ October 2016 
Aida Kesuma Azmin, Mohd Hisyamuddin Kassim, Fadzidah Abdullah, \& Alliyah Nur Zafirah Sanusi

Architectural Heritage Restoration of Rumah Datuk Setia Via Mobile Augmented Reality Restoration

\section{INTRODUCTION}

Architectural heritage restoration normally comes in physical forms, which requires commitments in terms of time, cost, and energy. Physical restoration of a building of authentic values entails careful handling so as not to damage the original building elements. Thus, to restore architectural heritage virtually is perceived as significant to "preserve, protect and interpret" cultural and building heritage (Noh, Sunar \& Pan, 2009). This research proposes an alternative restoration technique to visualize architectural heritage information at the historical site by employing MARR application and integrating it with other potential enabling technologies.

In doing so, the research intends to develop MARR of the ruined rear house of Rumah Datuk Setia (Datuk Setia House), as a showcase of MARR at the heritage site. "MARR" is a term to describe the utilization of mobile devices, such as smartphone and tablet, to visualize architectural heritage information, which has been virtually restored in the database. Development of MARR involves a thorough study of the original run-down building representation, as many similarities as possible.

Since physical architectural heritage restoration is scarcely affordable, this alternative restoration technique would be established even though the original architectural heritage on the site is in ruin. It offers an extraordinaire experience showcasing the legacy of the priceless Malay - Colonial architectural heritage in its glory days.

\section{RUMAH DATUK SETIA}

Rumah Datuk Setia is distinctive among other colonial bungalows due to its hybrid architecture. Colonial influences' immersion into the local building tradition with prominent Islamic principles became the primary ideology underlying its design approach. The development in Perak and the British intervention in the local scene have brought new materials and architectural style to the design of local dwellings. The 86-years-old mansion sits within a sixteen acres land, in Kampung Enggor, Karai, Kuala Kangsar, Perak.

\section{Historical Architectural Components}

Built approximately in the 1930s, the house was believed to be purposely designed by a British architect for the village chief, Penghulu Endut. Rumah Datuk Setia is divided into two main buildings: front and rear.

The front facade accentuates the house's characters - carefully adapted in response to his personality. As one approaches towards the mansion, one would notice this symmetrically designed building embraces a hybrid of Colonial and Traditional Malay architecture, embellished with decorative motifs, which portrays the owner's stature. The bungalow's grandeur scale is inspired by neoclassical public buildings and palace designs in Malaysia during the period. 
PLANNING MALAYSIA

Journal of the Malaysia Institute of Planners (2017)

The most prominent feature is the entrance porch (porte cochére), with Greek-style Corinthian capital using Setawar leaf motifs and cornice detailing on the entablature, on top of paired masonry columns. Its colonial architecture is indicated by the plastered brick masonry external walls and columns, originally in peach colour; and symmetrically protruding polygonal verandas (anjung) on both sides with the same column design. Floral motifs of Lotus flower and Setawar leaf symmetrically and repetitively enhance the arches.

Decorative floral ornaments at the fascia board and above the window lintels enhance the elegance of the building's appearance. Another interesting architectural feature is the trefoil arches discernible throughout the ground floor above the windows, which are uniformly glazed with small panes, and regularly spaced with arched mouldings at the top. The space planning demonstrates colonial characters through the formal and symmetrical layout. The front house layout is designed mainly for administration, whilst the upper floor and rear house are the family's dwelling areas.

In contrast, the rear building is instilled with traditional Malay architecture with square and cylindrical masonry columns at the ground level and common timber post-and-beam frameworks on the upper floor, with bigger and higher scale to adapt with the proportion of the colonial domain. Rafter boards (papan sisek), wooden lattice walls, lattice above openings and Malay floral motifs were carved onto the fascia boards. The open-plan space planning on the upper level depicts the traditional space division of a typical Malay house, with the selang (hallway) as a transitional space between the front and rear house; and the kitchen at the back. This space also includes a set of staircases at the back entrance, and another ladder on the east side, which leads straight into the kitchen.

\section{RUMAH DATUK SETIA RESTORATION}

The focus of the MARR is at the rear house, which is in a dilapidated state. Due to the lack of maintenance by the owner(s), major defects are apparent on floors, walls, roof structure, as well as finishes. The timber lattice walls at the ground floor are missing, leaving only traces of low-height brick masonry walls of about $580 \mathrm{~mm}$. Square brick masonry and round Doric style columns on the ground support the timber beams and floor joists on the upper floor. Also, there is evident of classical ornament below the timber beams acting as light holder below the upper floor joists. There was turquoise painted horizontal timber strip walls and panelled ceilings at the top floor interior. The walls, including openings, have been destroyed by termites. The roof systems are severely damaged, and cracks are visible on the leftover roof tiles. 
Aida Kesuma Azmin, Mohd Hisyamuddin Kassim, Fadzidah Abdullah, \& Alliyah Nur Zafirah Sanusi Architectural Heritage Restoration of Rumah Datuk Setia Via Mobile Augmented Reality Restoration

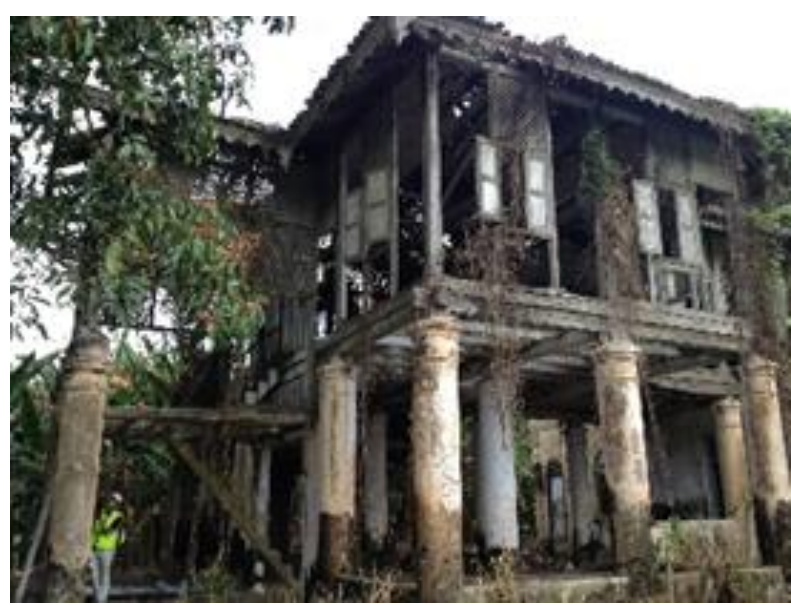

Figure 1 The Rear House of Rumah Datuk Setia

\section{METHODOLOGY}

The research is based on action research where the researchers are directly involved in the process of establishing the MARR of Rumah Datuk Setia. There are three stages; data gathering, action planning and measuring. These processes guide the researcher to unfold the relations between architectural heritage information and virtual heritage $(\mathrm{VH})$ reconstruction by categorizing the architectural building components. The researchers also adapt mobile augmented reality (AR) and other enabling technologies to assist MARR for on-site tour. While exploring the MARR on-site, the researchers synthesize the findings based on the technical issues, challenges and limitations.

\section{VIRTUAL HERITAGE (VH) AND AUGMENTED REALITY TECHNOLOGY}

The AR technologies can be considered as a practical and successful approach of combining the Virtual Reality (VR) into the real environment. It inspires "Architecture, Engineering and Construction" (AEC) (Wang, 2009) as well as "Architectural Reconstruction and Restoration" (ARR) to look into the new possibility of combining the VH setting with the physical characteristics and tools through the AR technologies. The aim is to offer "Experiencing Architecture" (Raynsford, 2016) by overlaying the VH with the "Real Environment" (RE).

The early AR reconstruction and restoration such as "Geist" (Kretschmer et al., 2001) and "Archeoguide" (Vlahakis et al., 2002) promised a new way of reconstructing and restoring the architectural heritage, which allows the visitors to experience the Heidelberg Castle while walking, guided by the electronic guide at the archaeological site of Olympia. The $\mathrm{VH}$ also plays an active role in reconstructing the monument and verifying fragments of the Parthenon (Papaioannou, Karabassi \& Theoharis, 2001) and restoring some buried artefacts 
PLANNING MALAYSIA

Journal of the Malaysia Institute of Planners (2017)

at the Museum of Terra Cotta Warriors and Horse (Zheng \& Zhang, 1999). Regarding touring on the historical site, iTacitus established the MAR guide for a historical sight, which applied historical media as augmentation layers (Zoellner et al., 2007). The aim is to use 2D feature-tracking method for exterior exploration.

Thus, the research fully utilizes the role of VH with architectural heritage information contents and overlays them with the historic site. This alternative technique promises a new way of architectural heritage documentation, history and culture resources; while giving the opportunity to simultaneously visualizing and reconstructing the lost architectural heritage, and also experiencing the architectural heritage without risk of damage as well as enhancing the virtual tourism (El-Hakim et al., 2004).

\section{AR and Other Enabling Technologies}

The development of AR technologies is mostly related to other enabling technologies. The research attempts to unfold these techniques, which could assist MARR regarding localization, User Interface (UI) design, online environment and mobile device technologies.

In term of localization, the usage of GPS, RFID, UWB, SF, SLAM (Hammad, Wang \& Mudur, 2009; Razavi \& Haas, 2011a; 2011b; Shahi et al., 2012; Castle, Klein \& Murray, 2008) and Barcoding in AR application have improved the tracking, especially on site location. The AR application is also integrated with Natural User Interface (NUI), which fully utilizes the human movement and gesture as a medium of interaction such as kinaesthetic control, SixthSense, iHelmet, ARCADE and KinÊtre (White, Lister \& Feiner, 2007; Tonn, Petzold \& Donath, 2008; Mistry \& Maes, 2009; Yeh, Tsai \& Kang, 2012; Stein, 2012; Chen, Izadi \& Fitzgibbon, 2012). In accessing the information, AR application integrates with Cloud Computing environment such as CloudBIM and SOA4BIM that can be accessed at anytime and anywhere (Redmond et al., 2012; Møller \& Schwartzbach, 2006). Regarding devices, there are many AR research application, which use smart phones, tablets, HMD or Glasses (Papagiannakis \& Magnenat-Thalmann, 2007; Jang, 2009; Goldman, 2012). These mobile devices are smaller, affordable and powerful, and offer highresolution display, which can be utilised at the on-site tour.

Thus, these enabling technologies provide an insight to the research proposal for the architectural restoration method using computer generated visual algorithms and its deployment to the AR application for the mobile device such as smartphone and tablet. This AR application is supported by cloud computing and geo-location where all VH information is stored in database and GPS to track the information about location and position of the real object and overlaid onto the $\mathrm{VH}$. 
Aida Kesuma Azmin, Mohd Hisyamuddin Kassim, Fadzidah Abdullah, \& Alliyah Nur Zafirah Sanusi

Architectural Heritage Restoration of Rumah Datuk Setia Via Mobile Augmented Reality Restoration

\title{
MARR AND ITS REQUIREMENTS
}

MARR is a term used to describe the application of mobile devices, such as smartphone and tablet, to visualize Augmented Reality (AR) model, which has been virtually restored. VH is established concerning the original run-down building, representing as much similarity as possible. Since physical architectural heritage restoration could be highly expensive and resource consuming, this alternative technique may serve building archaeologists, as well as tourists in restoring or experiencing the precious architectural heritage. In developing the MARR, the research highlights components such as architectural heritage information, AR application, MAR, Cloud Computing (CC) and Internet connection as the design ingredients for a design decision.

\begin{abstract}
AR Application
In developing the $\mathrm{VH}$, the research uses SketchUp Pro 2013 as a tool to reconstruct and restore the ruined rear house of Rumah Datuk Setia. The software is integrated with AR-media Plugin, which allows VH to be visualized out of Virtual Environment (VE) by connecting the webcam and printed markers or GPS. The VH can be visualized through a personal computer or mobile devices such as smartphone or tablet.
\end{abstract}

\section{MAR Devices and NUI}

The MARR file is a stand-alone and compatible for all common mobile platforms such as IOS and Android. The AR-media Player can be downloaded from App Store or Play Store by using mobile devices such as smartphone and tablet and stored into AR-media Player library. The user can interact using NUI to navigate or touring on the historical site at Karai, Kuala Kangsar since AR-media Player supports geo-location to visualize the $\mathrm{VH}$ without printed marker.

\section{Architectural Heritage Information}

The MARR emphasizes on the accuracy and photorealism 3D Virtual Heritage. In measuring and restoring the rear house of Rumah Datuk Setia, the research applied contact method (Remondino \& El-Hakim, 2006) involving measuring, tracing, scrubbing and moulding. For the photorealistic AR, the MARR models use existing UV mapping for adding details of the VH.

\section{Online Database}

The online database is the supporting unit of MAR Restoration model, which is accessible by the user and system administrator. The MARR files can be downloaded from the online database. The files can be categorized into the spatial organization, building components, construction, ornamentation and decoration. All MARR files are assigned with metadata descriptions. The idea is to facilitate 
MARR, especially on-site tour in searching the architectural heritage information.

Table 1 The Layer of Architectural Heritage Information

\begin{tabular}{cll}
\hline No & Architectural Characteristics & Restoration \\
\hline 1 & Spatial Organization & Hallway (Selang) \\
& & Kitchen (Dapur) \\
& & Dining Space \\
2 & Building Components & Wall, Partition, Floor, Ceiling \\
& & Door, Window, Top Hung \\
& & Staircase, Railing \\
3 & Construction & Footing, Foundation \\
& & Column, Beam \\
& & Roofing \\
4 & Ornamentation/Decoration & Wall, Partition, Floor, Ceiling \\
& & Staircase, Railing \\
& & Column, Beam \\
5 & Material/Specification & Wood \\
& & Masonry \\
& & etc. \\
\hline
\end{tabular}

\section{Internet Connection}

The wireless connection is imperative to link the database and the mobile devices. The aim is the real-time transfer of MARR files during the site tour and personalized the information based on the user interest.

\section{MARR STRUCTURE AND FLOW}

The MARR technical structure and flow can be categorized into five (5) stages as follows (Figure 2).

Stage 1 refers to physical documentation process where it involves architectural heritage information through contact method, literature reviews and interviews. The UV mapping technique of original material and texture for $\mathrm{VH}$.

Stage 2 refers to the development of MARR via the $\mathrm{VH}$ reconstruction by considering the layer of architectural heritage information. The $\mathrm{VH}$ is designed to be deployed on the mobile device with geo-location features.

Stage 3 refers to the development of website design supported by cloud database to provide a real-time transfer of MARR. All MARR files are stored in cloud database and are easily accessed during the on-site touring.

Stage 4 refers to MARR model generated by the MAR engine. This MAR engine tracks and recognizes the geo-location on the historical site then loads the MARR model on the mobile display.

Stage 5 refers to the on-site tour of the historical site by navigating the MARR model on the display screen by NUI design while touring the historic site. 
Aida Kesuma Azmin, Mohd Hisyamuddin Kassim, Fadzidah Abdullah, \& Alliyah Nur Zafirah Sanusi Architectural Heritage Restoration of Rumah Datuk Setia Via Mobile Augmented Reality Restoration

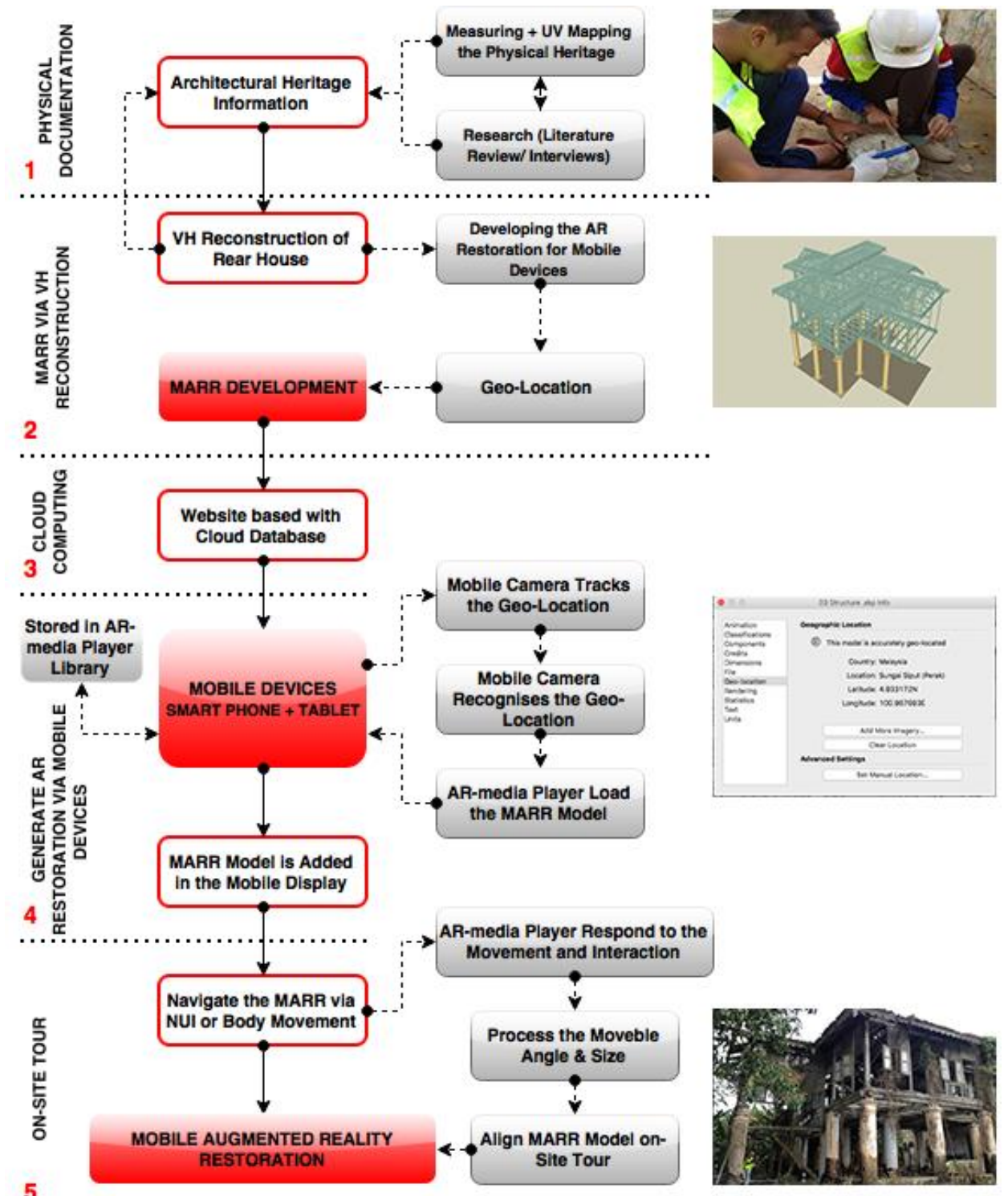

Figure 2 MARR Technical Structure and Flow

\section{DISCUSSION AND SUGGESTIONS}

In developing the MARR model, accuracy of geo-location is the most important factor to determine the alignment between VH and RE. However, mobile tracking technologies using GPS have difficulty to identify the geo-location on the large environment, and consequently effecting the precise position and orientation of 
PLANNING MALAYSIA

Journal of the Malaysia Institute of Planners (2017)

the MARR model as well as Rumah Datuk Setia. As an alternative, the research suggests using AR-media SDK application to track the 3D object in the RE (Battini \& Landi, 2015). The aim is to improve mobile tracking by establishing the connection between the architectural heritage images and $\mathrm{VH}$ geometric features.

Regarding visualization, MARR suffers from poor visualization quality and is too detail to operate with the complex layer of architectural heritage information. Consequently, it affects the navigation performance of MARR such as lagging during the on-site touring. The research suggests that $\mathrm{VH}$ reconstruction should adopt Building Information Modelling (BIM) as a tool to manage the complex architectural heritage information (Fai et al., 2011). The aim is to categorize and minimize the complexity of object entities without losing any architectural heritage information.

\section{CONCLUSION}

The research presents architectural heritage restoration by employing MAR with other enabling technologies to assist the architectural archaeologists and tourists. MAR provides the alternative technique for architectural heritage restoration of the ruined rear house of Rumah Datuk Setia. The research also highlights the technical structure and the flow that need to be considered in producing the MARR as well as the challenges and limitations of the technology faced throughout the research. The MARR offers new hope for architectural heritage restoration since physical restoration can be highly expensive. It promises an enriched experience and features the legacy of the Malay - Colonial Architecture even though the original architectural heritage on the site is in ruined.

\section{ACKNOWLEDGEMENTS}

The researchers are grateful to all the Heritage Studies' colleagues and students for their cooperation and assistance in documenting architectural heritage information of Rumah Datuk Setia. 
Aida Kesuma Azmin, Mohd Hisyamuddin Kassim, Fadzidah Abdullah, \& Alliyah Nur Zafirah Sanusi

Architectural Heritage Restoration of Rumah Datuk Setia Via Mobile Augmented Reality Restoration

\section{REFERENCES}

Battini, C., \& Landi, G. (2015). 3D tracking based augmented reality for cultural heritage data management. The International Archives of Photogrammetry, Remote Sensing and Spatial Information Sciences, 40(5), 375-379.

Castle, R., Klein, G., \& Murray, D. W. (2008). Video-rate localization in multiple maps for wearable augmented reality. 12th IEEE International Symposium on Wearable Computers, September 28 - October 1, 2008, Pittsburgh, USA.

Chen, J., Izadi, S., \& Fitzgibbon, A. (2012). KinÊtre: animating the world with the human body. In Proceedings of the 25th annual ACM symposium on User interface software and technology. Cambridge, Massachusetts.

El-Hakim, S. F., Angelo Beraldin, J., Picard, M., \& Godin, G. (2004). Detailed $3 \mathrm{D}$ reconstruction of large-scale heritage sites with integrated techniques. Computer Graphics and Applications, IEEE, 24(3), 21-29.

Fai, S., Graham, K., Duckworth, T., Wood, N., \& Attar, R. (2011). Building information modelling and heritage documentation. In Proceedings of the 23rd International Symposium, International Scientific Committee for Documentation of Cultural Heritage (CIPA). Prague, Czech Republic.

Goldman, D. (2012). Google unveils "project glass" virtual-reality glasses. Money $(C N N)$.

Hammad, A., Wang, H., \& Mudur, S. P. (2009). Distributed augmented reality for visualizing collaborative construction tasks. Journal of Computing in Civil Engineering, 23(6), 418-427.

Jang, W. (2009). Utilization of ubiquitous computing for construction AR technology. Automation in Construction, 18(8), 1063-1069.

Kretschmer, U., Coors, V., Spierling, U., Grasbon, D., Schneider, K., Rojas, I., $\&$ Malaka, R. (2001). Meeting the spirit of history. In Proceedings of the 2001 Conference on Virtual Reality, Archeology, and Cultural Heritage. Glyfada, Greece.

Mistry, P., \& Maes, P. (2009). SixthSense: a wearable gestural interface. SIGGRAPH ASIA 2009. Yokohama, Japan.

Møller, A., \& Schwartzbach, M. I. (2006). An introduction to XML and Web technologies. Pearson Education.

Noh, Z., Sunar, M. S., \& Pan, Z. (2009). A review on augmented reality for virtual heritage system. In M. Chang, R. Kuo, Kinshuk, G.D. Chen \& M. Hirose (Eds.), Learning by playing. Game-based education system design and development (pp. 50-61). Alberta: Springer Berlin Heidelberg.

Papagiannakis, G., \& Magnenat-Thalmann, N. (2007). Mobile augmented heritage: Enabling human life in ancient Pompeii. International Journal of Architectural Computing, 5(2), 396-415. 
PLANNING MALAYSIA

Journal of the Malaysia Institute of Planners (2017)

Papaioannou, G., Karabassi, E., \& Theoharis, T. (2001). Virtual archaeologist: Assembling the past. Computer Graphics and Applications, IEEE, 21(2), 53-59.

Raynsford, A. (2016). From spatial feeling to functionalist design: contrasting representations of the Baroque in Steen Eiler Rasmussen's experiencing architecture. In A. Leach, J. Macarthur, M. Delbeke (Eds.), The Baroque in architectural culture, 1880-1980 (pp. 173-184). New York: Routledge.

Razavi, S. N., \& Haas, C. T. (2011a). Using reference RFID tags for calibrating the estimated locations of construction materials. Automation in Construction, 20(6), 677-685.

Razavi, S. N., \& Haas, C. T. (2011b). Reliability-based hybrid data fusion method for adaptive location estimation in construction. Journal of Computing in Civil Engineering, 26(1), 1-10.

Redmond, A., Hore, A., Alshawi, M., \& West, R. (2012). Exploring how information exchanges can be enhanced through cloud BIM. Automation in Construction, 24, 175-183.

Remondino, F., \& El-Hakim, S. (2006). Image-based 3D modeling: a review. The Photogrammetric Record, 21(115), 269-291.

Shahi, A., Aryan, A., West, J. S., Haas, C. T., \& Haas, R. C. (2012). Deterioration of UWB positioning during construction. Automation in Construction, 24, 72-80.

Stein, M. (2012). ARCADE: a system for augmenting gesture-based computer graphic presentations. SIGGRAPH 2012 Computer Animation Festival. Los Angeles, USA.

Tonn, C., Petzold, F., \& Donath, D. (2008). Put on your glasses and press right mouse button AR-based user interaction using laser pointer tracking. In Proceeding of the 26th conference on education in computer aided architectural design in Europe. Antwerp, Belgium.

Vlahakis, V., Ioannidis, N., Karigiannis, J., Tsotros, M., Gounaris, M., Stricker, D., Gleue, T., Daehne, P., \& Almeida, L. (2002). Archeoguide: an augmented reality guide for archaeological sites. IEEE Computer Graphics and Applications, 5, 52-60.

Wang, X. (2009). Augmented reality in architecture and design: potentials and challenges for application. International Journal of Architectural Computing, 7(2), 309-326.

White, S., Lister, L., \& Feiner, S. (2007). Visual hints for tangible gestures in augmented reality. In Proceedings of the 2007 6th IEEE and ACM International Symposium on Mixed and Augmented Reality. Washington, USA. 
Aida Kesuma Azmin, Mohd Hisyamuddin Kassim, Fadzidah Abdullah, \& Alliyah Nur Zafirah Sanusi

Architectural Heritage Restoration of Rumah Datuk Setia Via Mobile Augmented Reality Restoration

Yeh, K., Tsai, M., \& Kang, S. (2012). On-site building information retrieval by using projection-based augmented reality. Journal of Computing in Civil Engineering, 26(3), 342-355.

Zheng, J. Y., \& Zhang, Z. L.(1999). Virtual recovery of excavated relics. Computer Graphics and Applications, IEEE, 19(3), 6-11.

Zoellner, M., Stricker, D., Bleser, G., \& Pastarmov, Y. (2007). iTACITUS novel interaction and tracking paradigms for mobile AR. In D. Arnold (Ed.), The European research network of excellence in open cultural heritage (EPOCH) (pp. 110-117). Budapest: Archaeolingua. 